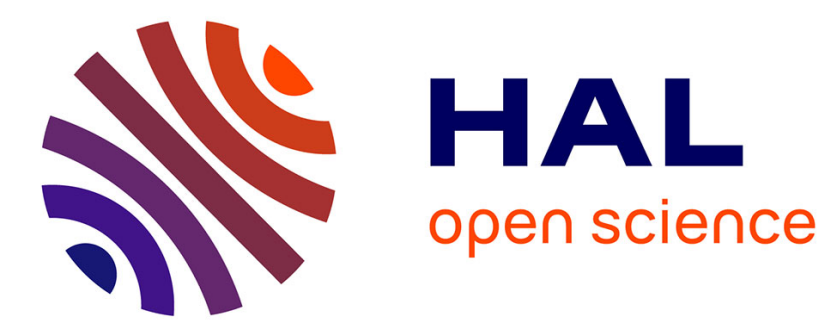

\title{
Robust hybrid observer for IBC based on $\mathrm{Z}(\mathrm{TN})$-Observability
}

Imen Mrad, Abdessamad Abdelhedi, Jean-Pierre Barbot, Lassaad Sbita

\section{To cite this version:}

Imen Mrad, Abdessamad Abdelhedi, Jean-Pierre Barbot, Lassaad Sbita. Robust hybrid observer for IBC based on Z(TN)-Observability. International Conference on Green Energy Conversion Systems, Mar 2017, Hammamet, Tunisia. hal-01710566

\section{HAL Id: hal-01710566 https://hal.science/hal-01710566}

Submitted on 16 Feb 2018

HAL is a multi-disciplinary open access archive for the deposit and dissemination of scientific research documents, whether they are published or not. The documents may come from teaching and research institutions in France or abroad, or from public or private research centers.
L'archive ouverte pluridisciplinaire HAL, est destinée au dépôt et à la diffusion de documents scientifiques de niveau recherche, publiés ou non, émanant des établissements d'enseignement et de recherche français ou étrangers, des laboratoires publics ou privés. 


\section{Robust hybrid observer for IBC based on $\mathrm{Z}(\mathrm{TN})$-Observability}

\author{
Imen Mrad \\ Research \\ Unit of Photovoltaic, \\ Wind and \\ Geothermal Systems \\ National Engineering \\ School of Gabes, \\ University of Gabes \\ St Omar Ibn-Elkhattab. \\ Zrig. \\ Gabes 6029, \\ Tunisia \\ Email:imenmrading@gmail.com
}

\author{
Abdessamad Abdelhedi \\ Research \\ Unit of Photovoltaic, \\ Wind and \\ Geothermal Systems \\ National Engineering \\ School of Gabes, \\ University of Gabes \\ St Omar Ibn-Elkhattab, \\ Zrig. \\ Gabes 6029, \\ Tunisia \\ Email:Abdelhedy@yahoo.fr
}

\author{
Jean Pierre Barbot \\ Professor of \\ Universities \\ at ENSEA \\ Director of \\ QUARTZ EA 7393 \\ ENSEA, \\ 6 Avenue \\ du Ponceau \\ 95014, \\ Cergy Pontoise, \\ France \\ Email: barbot@ensea.fr
}

\author{
Lassaad Sbita \\ Professor \\ of Universities at ENIG \\ Director of \\ SPEG UR11ES82 \\ National \\ Engineering \\ School of Gabes, \\ University of Gabes \\ St Omar Ibn-Elkhattab, \\ Zrig, Gabes 6029 , \\ Tunisia
}

\begin{abstract}
In this paper, a hybrid observer for interleaved boost converter is proposed. This converter is amid of new structures which based on parallaling converters, characterized by a strong currents with high switching frequencies. After recalling the dynamical equations of the converter, its hybrid dynamical behaviour and advantages are illustrated. This lineair switched system has unobservable configuration modes linked to particular switching sequences. By using a new concept called the Z(Tn)observability this problem was solved. The proposed observer is based on the homogeneous observer alghorithm coupled with an estimator. The perfermances of the designed observer are highlighted by simulation studies in MATLAB/Simulink, a finite time convergence is obtained even in the presence of input variation.
\end{abstract}

Keywords-hybrid observer, interleaved hoost converter, hybrid behaviour, $Z(T n)$-observability, homogeneous observer.

\section{INTRODUCTION}

A hybrid dynamic system (HDS) is a system that switches belween various operation modes where each mode is governed by its own dynamic law, it's modeled as a combination of continuous and discrete event subsystems. Among these systems interleaved DC-DC Converter, where interleaving is a technique that we can be implimented by parallelling the converters, it has been widely used in power converter in recents years [1] [2] [3], typical benefics of interleaving techniques include reduced device stress by separating power into each discrets phases [4], reduced filter size by increasing effective frequency, and alleviation of the effects of current ripple [5]. another advantage is the ability to operate the converter when a failure occurs in one cell as well as possibility to add new cells to the converter with minimum efforts. In this paper we take the example of interleaved boost converter (IBC) that has been studied for applications to power-factor correction circuit [6] and us the interface between fuel cells, photovoltaique arrays or battery sources and the DC bus of $A C$ inverters [7] [8], the IBC is composed of several identical boost converters connected in parallel. By virtue of paralleling the converters, the input current can be shared among the cells or phases, so that high reliability and efficiency in power electronic systems can be obtained. On ather hand several approches has been considered to control and observation the IBC. First, models have been designed to describe their averging [9]. instantaneous [10] or harmonic [11] behaviour. These various models were used for development of control laws, us [6] propose a controller based on Lyapunov-likelihood control technique, state feedback control method is designed in $\lceil 12\rceil$. Since any power converter is an hybrid system these methods does not take into account the currents control alghorithme. Therefore a state vector of IBC is not observable al any time. In this context many studies have treated the problem of hybrid observability of systems with unobservable operating modes during switching cycles [13] [14] [15][16]. Indeed the hybrid observability shows that a switched system wich has an unobservable subspaces for some operation modes is observable in a hybrid sense. Thus, it can be proved that the hybrid observability of a switched system does not necessarily imply the existence of a procedure for reconstructing the state in the case where the process goes through an operation mode for which a subspace is unobservable. However hybrid observers synthesis which takes into account unobservable states was widely studied these last decades and it remains a scientific problem and very few results exist in the literature. The consideration of such problem in observers' synthesis was proposed in [17], nevertheless this work studies a particular case of switched systems whose unobservable states are constant, and this particular condition is validated for some power converters as the serial multicellular converters. Besides in [18] [19] the authors treat the synthesis of hybrid observers in general with either observable or unobservable subspace but the disadvantage of this observer is that its synthesis and its implementation in practice is difficult. The purpose of this paper is to design an hybrid observer based on the homogenous observer alghorithm $\lceil 20\rceil$ coupled with an estimator using 
the new concept $Z(T n)$-observability [21], whose under some condtions there exists a time sequence called hybrid time trajetory [22], after which we can observe all the state vector. The paper is organised as follows: The IBC converter modelling is presented in section 2; The analysis of a hybrid observability of IBC converter using the concept of Z(TN)observability can be found in Section 3. Section 4 is devoted to the observer design. To illustrate the theoretical results, simulation results are presented in Section 5. Finally, a conclusion is given in Section 6.

\section{InTERLEAVEd Boost CONVERTER MOdELling}

Interleaving is a technique which is implemented by paralleling the converters, thus the Interleaved Boost Converter consists of two single Boost converters connected in parallel, us shown in Fig. 1, where $V_{i n}$ is the input voltage, $L_{1}$ and $L_{2}$ are magnetizing inductances, $q_{1}$ and $q_{2}$ are semiconductor switches, $D 1$ and $D 2$ are diodes, $C$ is an output capacitor, and $R$ is a load resistance. Generaly for the circuit modelling, the

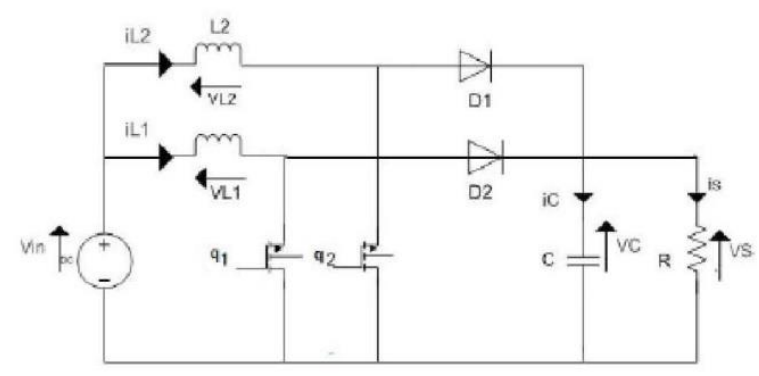

Fig. 1: Circuit of the IBC

capacitor voltage and inductors current are considered as the states variables.

$$
\begin{gathered}
x=\left[i L_{1}, \mathrm{iL}_{2}, \mathrm{~V} c\right]^{T}=\left[x_{1}, x_{2}, x_{3}\right]^{T} \\
y=x_{3} \\
\left\{\begin{array}{l}
\dot{x}=f_{q}(x) \\
y=x_{3}
\end{array}\right.
\end{gathered}
$$

For $q_{1}=1, q_{2}=0$

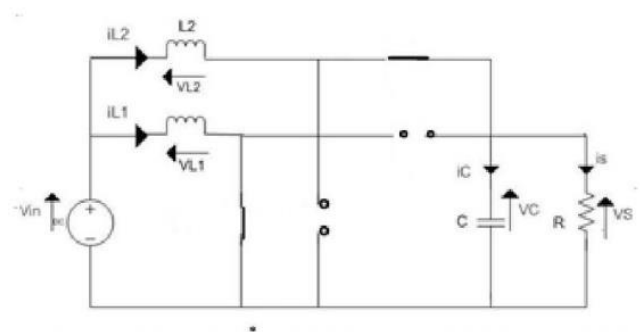

Fig. 2: Equivalent circuit of IBC for mode 1

$$
f_{1}\left\{\begin{array}{l}
\dot{x}_{1}=\frac{1}{L_{1}} V_{i n} \\
\dot{x}_{2}=\frac{1}{L_{2}} V_{i n}-\frac{1}{L_{2}} x_{3} \\
\dot{x}_{3}=\frac{1}{C} x_{2}-\frac{1}{R C} x_{3}
\end{array}\right.
$$

$$
y=x_{3}
$$

And for $q_{1}=0, q_{2}=1$

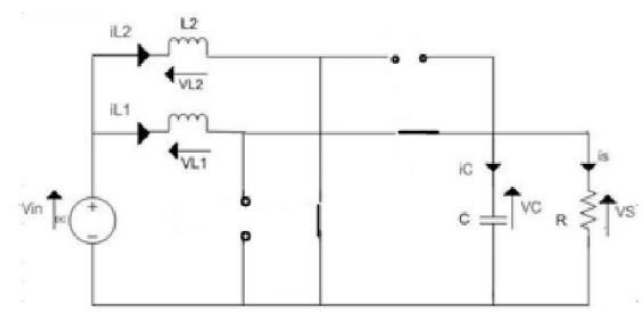

Fig. 3: Equivalent circuit of IBC for mode 2

$$
f_{2}\left\{\begin{array}{l}
\dot{x}_{1}=\frac{1}{L_{1}} V_{i n}-\frac{1}{L_{1}} x_{3} \\
\dot{x}_{2}=\frac{1}{L_{2}} V_{i n} \\
\dot{x}_{3}=\frac{1}{C} x_{1}-\frac{1}{R C} x_{3} \\
y=x_{3}
\end{array}\right.
$$

Looking for the hybrid model of the IBC converter, we introduce the discrete variables $q_{1}, q_{2}$

$$
f=f_{1} \times\left(1-q_{2}\right)+f_{2} \times\left(1-q_{1}\right)
$$

We obtain:

$$
\left\{\begin{array}{l}
{\left[\begin{array}{l}
\dot{x}_{1} \\
\dot{x}_{2} \\
\dot{x}_{3}
\end{array}\right]=\left[\begin{array}{ccc}
0 & 0 & -\frac{1-q_{1}}{L_{1}} \\
0 & 0 & -\frac{1-q_{2}}{L_{2}} \\
\frac{1-q_{2}}{C} & \frac{1-q_{1}}{C} & \frac{1}{R C}
\end{array}\right]\left[\begin{array}{l}
x_{1} \\
x_{2} \\
x_{3}
\end{array}\right]} \\
+\left[\begin{array}{lll}
\frac{1}{L_{1}} & \frac{1}{L_{2}} & 0
\end{array}\right]^{T} V_{i n} \\
y=\left(\begin{array}{lll}
0 & 0 & 1
\end{array}\right)\left[\begin{array}{lll}
x_{1} & x_{2} & x_{3}
\end{array}\right]^{T}=V_{o}
\end{array}\right.
$$

\section{OBSERVABILITY ANALYSIS}

Let us consider the following class of system:

$$
\begin{aligned}
& \dot{\xi}=f_{q}(t, \xi, u), q \in Q,, \xi \in \Re^{n}, u \in \Re^{m} \\
& Y=h_{q}(t, \xi, u)
\end{aligned}
$$

Where $Q$ is a finite index set, $f_{q} \Re \times \Re^{n} \times \Re^{m} \rightarrow \Re^{n}$ is sufficiently smooth, all dwell time intervals, $\left[t_{i, 0}, t_{i, 1}\right]$, between two switchings of the structure satisfy $t_{i, 1}-t_{i, 0}>\tau_{\min }$ for some $\tau_{\text {min }}>0$ (this assumption excludes Zeno phenomena [23]. For the input $u$ in any time interval $\left[t_{i, 0}, t_{i, 1}\left[\subseteq\left[t_{\text {ini }}, t_{\text {end }}[\right.\right.\right.$, we assume that $u(t)$ is bounded and sufficiently smooth.

For switched systems, the concept of observability and observer design are strongly related to the sequence of switching, thus it is important to recall the definition of hybrid time trajectory

Definition 1: [24] [22] A hybrid time trajectory is a finite or infinite sequence of intervals $T_{N}=\left(I_{i}\right)_{i=0}^{N}$, such that:

- $I_{i}=\left[t_{i, 0}, t_{i, 1}[\right.$, for $0 \leq i<N$;

- For all $i<N t_{i, 1}=t_{i+1,0}$

- $t_{0,0}=t_{\text {ini }}$ et $t_{N, 1}=t_{\text {end }}$

Moreover, $\langle T N\rangle$ is the ordered list of $q$ associated to $T N$ ( $\left.q_{0}, \ldots, q_{N}\right)$ with $q_{i}$ the value of $q$ during the time interval $I_{I}$ 
The concept of $Z(T N)$-Observability was proposed for non linears systems and switching systems. This notion has the particularity of taking into account the partial observability of the state and the hybrid time trajectory, the observability for each partial model and deduces the observability or unobservability with respect to switching sequence and the estimation of the parameters by a dynamic extension.

Definition 2: [21] Consider a system (1) and a variable $z=Z(t, \xi, u)$. Let $\left(t, \xi^{1}(t), u^{1}(t)\right)$ be a trajectory in $U$ with a hybrid lime trajectory $T N$ and $\langle T N\rangle$. Suppose for any trajectory, $\left(t, \xi^{2}(t), u^{2}(t)\right)$, in $U$ with the same $T N$ and $\langle T N\rangle$, the equality:

$$
h\left(t, \xi_{1}(t), u_{1}(t)\right)=h\left(t, \xi_{2}(t), u_{2}(t)\right)
$$

implies

$$
Z\left(t, \xi_{1}(t), u_{1}(t)\right)=Z\left(t, \xi_{2}(t), u_{2}(t)\right)
$$

Then we say that $z-Z(t, \xi, u)$ is $Z(\mathrm{TN})$-observable along the trajectory $\left(t, \xi^{1}(t) \cdot u^{1}(t)\right)$.

For a fixed hybrid time trajectory $T N$ and $\langle T N\rangle$, if $z=$ $Z(t, \xi, u)$ is $Z(\mathrm{TN})$-observable along all trajectories in $U$, then, $\tilde{z}=Z(t, \xi, u)$ is said to be $Z(\mathbf{T N})$-observable in $U$.

Suppose for any trajectory $(t, \xi(t), u(t))$ in $U$, there always exists an open set $U_{1} \subset U$ so that $(t, \xi(t) \cdot u(t))$ is contained in $U_{1}$ and $z=Z(t, \xi, u)$ is $\mathrm{Z}(\mathbf{T N})$-observable in $U 1$. Then, $z=Z(t, \xi, u)$ is said to be locally $Z(\mathbf{T N})$-observable.

The dimension of $z$ variable is denoted by $n_{3}$. A linear projection $P$ is defined by:

$$
P:\left[\begin{array}{l}
z_{1} \\
\vdots \\
z_{n_{z}}
\end{array}\right] \rightarrow\left[\begin{array}{ccccc}
\delta_{1} & 0 & 0 & \ldots & 0 \\
0 & \delta_{2} & 0 & \ldots & 0 \\
. & . & . & . & \cdot \\
0 & 0 & 0 & \ldots & \delta_{n_{z}}
\end{array}\right]\left[\begin{array}{l}
z_{1} \\
\vdots \\
z_{n_{z}}
\end{array}\right]
$$

where $\delta_{i} . \mathrm{i}=1,2, \ldots, \mathrm{n}_{z}$, is zero or one. The complement of $P$ is called $\bar{P}$ (projecting $\approx$ to the variables eliminated by $P$ ).

Proposition 1: [25] Consider the system (1) and a fixed hybrid time trajectory $T N$ and $\langle T N\rangle$. Let $U$ be an open set in lime-slate-control space. Suppose $Z(t, \xi(t), u(t)) \in \Re^{N_{z}}$ is always continuous under any admissible control inpul.

Suppose there exists a sequence of projections $P i$. i $-0,1$, $\ldots, 11$ z such that

(1) given any $0 \leq i \leq N, P i Z(t, x i, u)$ is Z-observable in $U$ on the subinterval $t \in \mid t_{i, 0}, t_{i, 1}$;

(2) $\operatorname{Rank}\left[P_{0}^{T} \ldots P_{N}^{T}\right]=n_{\text {; }}$;

(3) $\frac{d P_{i} Z(t, \xi(t), u(t))}{d t}=0$ for $t \in\left[t_{i, 0}, t_{i, 1}\right.$ and $(t, \xi(t), u(t)) \in$ $U$

Then, $z=Z(t, \xi, u)$ is $Z(\mathbf{T N})$-observable in $U$ with respect to the hybrid time trajectory $T N$ and $\langle T N\rangle$.

\section{A. observability of the $I B C$}

Considering the observability matrix based on $q_{1} q_{2}$ of this hybrid system:

$$
\begin{aligned}
& y=x_{3} \\
& \dot{y}-\dot{x}_{3}-\frac{1}{C}\left(1-q_{1}\right) x_{1}+\frac{1}{C}\left(1-q_{2}\right) x_{2}-\frac{1}{R C} x_{3} \\
& \ddot{y}=\ddot{x}_{3}=-\frac{1}{R C^{2}}\left(1-q_{1}\right) x_{1}-\frac{1}{R C^{2}}\left(1-q_{2}\right) x_{2} \\
& -\left(\frac{1}{L_{1} C}\left(1-q_{1}\right)^{2}+\frac{1}{L_{2} C}\left(1-q_{2}\right)^{2}\right) x_{3} \\
& d O(3)=\left[\begin{array}{ccc}
0 & 0 & 1 \\
a & b & c \\
d & e & f
\end{array}\right]
\end{aligned}
$$

With:

$$
\begin{aligned}
& a=\frac{1}{C}\left(1-q_{1}\right) \\
& b=\frac{1}{C}\left(1-q_{2}\right) \\
& c=-\frac{1}{R C} \\
& d=-\frac{1}{R C^{2}}\left(1-q_{1}\right) \\
& \epsilon=-\frac{1}{R C^{2}}\left(1-q_{2}\right) \\
& f=-\left(\frac{1}{L_{1} C}\left(1-q_{1}\right)^{2}+\frac{1}{L_{2} C}\left(1-q_{2}\right)^{2}\right)
\end{aligned}
$$

for $q_{1}=1$

$$
\left\{a=d=\frac{1}{C}\left(1-q_{1}\right)=0\right\}
$$

then $x_{1}$ is unobservable.

for $q_{2}=1$

$$
\left\{b=e=\frac{1}{C}\left(1-q_{2}\right)=0\right\}
$$

then $x_{2}$ is unobservable.

According to definition 2 , it can be said that the state $x_{1}$ is observable in the hybrid sense if at least the hybrid time trajectory containes one mode with $q_{1}=0$. The same for state $x_{2}$ is observable in the hybrid sense if at least the hybrid time trajectory containes one mode with $q_{2}=0$

\section{OBSERVER DFSIGN}

In this paper, the proposed method is based on the Homogeneous Observer [26] [20]. To present the observer design some definitions are given.

Definition 3: [20] A function $G: \Re^{n} \longrightarrow \Re$ is homogeneous of degree $d$ with respect to the weights $\left(r_{1}, \ldots, r_{n}\right) \in$ $\mathfrak{r}^{n}>0$

$$
G\left(\lambda^{r_{1}} x_{1}, \ldots, \lambda^{r_{n}} x_{n}\right)=\lambda^{d} G\left(x_{1}, \ldots, x_{n}\right)
$$

for all $\lambda>0$

Definition 4: A vector field $g$ is homogeneous of degree $d$ with respect to the weights $\left(r_{1}, \ldots, r_{n}\right) \in \Re_{>0}^{n}$ if, for all $1 \leq i \leq n$ the ith component $g_{i}$ is a homogeneous function of degree $r_{i}+d$, that is,

$$
g_{i}\left(\lambda^{r_{1}} x_{1}, \ldots, \lambda^{r_{n}} x_{n}\right)=\lambda^{r_{i}+d} g_{i}\left(x_{1}, \ldots, x_{n}\right)
$$




\section{A. Problem formulation}

Let us consider system with the canonical observable form

$$
\left\{\begin{array}{l}
\dot{z}=A z+f\left(y, u, \dot{u}, \ldots, u^{r}\right) \\
y=C z
\end{array}\right.
$$

where $z \in \Re^{n}$ the state, $r \in N>0$, and

$$
\begin{gathered}
A=\left(\begin{array}{ccccc}
a_{1} & 1 & 0 & 0 & 0 \\
a_{2} & 0 & 1 & 0 & 0 \\
\vdots & 0 & 0 & 1 & 0 \\
a_{n-1} & 0 & 0 & 0 & 1 \\
a_{n} & 0 & 0 & 0 & 0
\end{array}\right) \\
C=\left(\begin{array}{lllll}
1 & 0 & 0 & 0
\end{array}\right)
\end{gathered}
$$

The homogeneous observer for this system is designed as:

$$
\begin{aligned}
\left(\begin{array}{c}
\dot{z}_{1} \\
\dot{z}_{2} \\
\vdots \\
\dot{\hat{z}}_{n-1} \\
\dot{\hat{z}}_{n}
\end{array}\right)=A\left(\begin{array}{c}
\hat{z}_{1} \\
\hat{z}_{2} \\
\vdots \\
\hat{z}_{n-1} \\
\hat{z}_{n}
\end{array}\right)+f\left(y, u, \dot{u}, \ldots, u^{(n)}\right) \\
\\
-\left(\begin{array}{c}
k_{1}\left\lceil e_{1}\right\rfloor^{\alpha_{1}} \\
k_{2}\left\lceil e_{1}\right\rfloor^{\alpha_{2}} \\
\vdots \\
k_{n-1}\left\lceil e_{1}\right\rfloor^{\alpha_{n-1}} \\
k_{n}\left\lceil e_{1}\right\rfloor^{\alpha_{n}}
\end{array}\right)
\end{aligned}
$$

where the function $\chi_{i}=k_{i}\left\lceil e_{1}\right\rfloor^{\alpha_{i}}$ is defined as $e=z-\hat{z}$ tends to zero in finite time [20].

Thus the observation errors dynamics is given by:

$$
\left\{\begin{array}{l}
\dot{e}_{1}=e_{2}+\chi_{1}\left(e_{1}\right) \\
\dot{e}_{2}=e_{3}+\chi_{2}\left(e_{1}\right) \\
\vdots \\
\dot{e}_{n-1}=e_{n}+\chi_{n-1}\left(e_{1}\right) \\
\dot{e}_{n}=\chi_{n}\left(e_{1}\right)
\end{array}\right.
$$

Let $\alpha_{1}=\alpha$

Lemma 1: If $\alpha>1-\frac{1}{n-1}$ the system (5) is homogeneous of degree $\alpha-1$ with respect to the weights $\{(i-1) \alpha-(i-2)\}_{1 \leq i \leq n}$ and $\alpha_{i}=i \alpha_{1}-(i-1), 1 \leq i \leq n$.

Procf 1: For the proof see [20].

\section{B. hybrid Observer for the $I B C$ converter}

A hybrid observer is synthesized, which is characterized by two coupled modes of operation. The first mode is the observation of the states of the system based on a homogeneous observer, and the second is the estimate of the unobservable states by knowing their dynamique.

$\hat{f}\left\{\begin{array}{l}\dot{\hat{x}}_{1}=\frac{1}{L_{1}} V_{i n}-\frac{1}{L_{1}}\left(1-q_{1}\right) \hat{x}_{3}-k_{1}\left\lceil x_{3}-\hat{x}_{3}\right\rfloor^{\alpha}\left(1-q_{1}\right) \\ \dot{\hat{x}}_{2}=\frac{1}{L_{2}} V_{i n}-\frac{1}{L_{1}}\left(1-q_{2}\right) \hat{x}_{3}-k_{2}\left\lceil x_{3}-\hat{x}_{3}\right\rfloor^{2 \alpha-1}\left(1-q_{2}\right) \\ \dot{\hat{x}}_{3}=\frac{1}{C}\left(1-q_{1}\right) \hat{x}_{1}+\frac{1}{C}\left(1-q_{2}\right) \hat{x}_{2}-\frac{1}{R C} \hat{x}_{3} \\ -k_{3}\left\lceil x_{3}-\hat{x}_{3}\right\rfloor^{3 \alpha-2}\end{array}\right.$
TABLE I: Parametres of the IBC

\begin{tabular}{|c|c|}
\hline Parameter & Value(unit) \\
\hline$L_{1}$ & $7210^{-6} \mathrm{H}$ \\
\hline$L_{2}$ & $7210^{-6} \mathrm{H}$ \\
\hline$C$ & $21710^{-6} \mathrm{~F}$ \\
\hline$R$ & $23 \Omega$ \\
\hline$V_{e}$ & 25 \\
\hline
\end{tabular}

Such as $\left\lceil x_{3}-\hat{x}_{3}\right\rfloor^{\alpha}=\left|x_{3}-\hat{x}_{3}\right|^{\alpha} \operatorname{sign}\left(x_{3}-\hat{x}_{3}\right)$

\section{SIMULATION AND RESULT}

The hybrid observer was tested on the model of the IBC converter in simulation using MATLAB environment. The observer model is implemented in open loop with computation step equal to $10^{-7} \mathrm{~s}$ and a IBC switching frequency $20 \mathrm{kHz}$. The parameters of the circuit are given in table 1 .

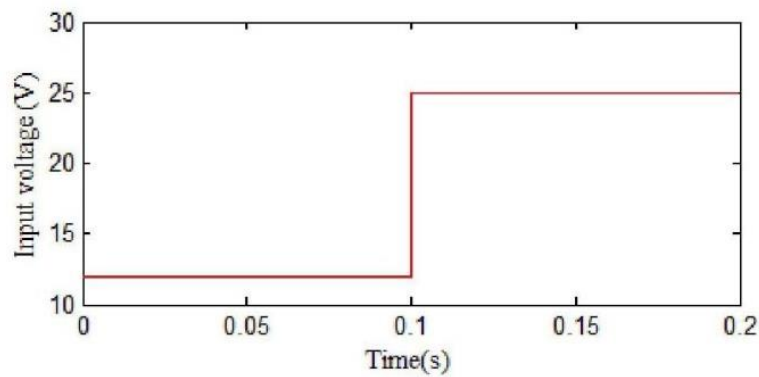

Fig. 4: Input signal

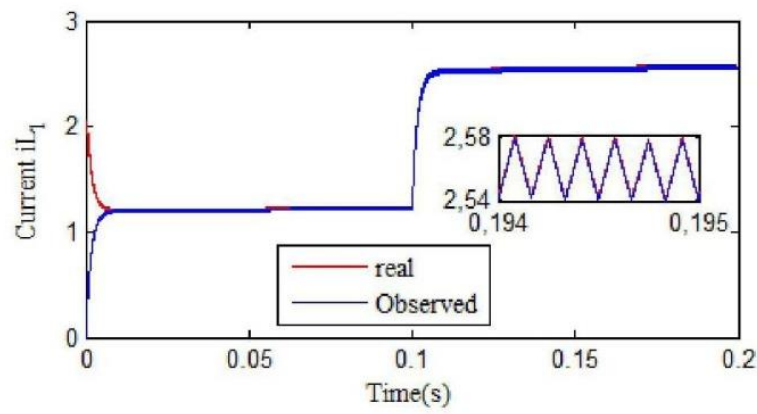

Fig. 5: Inductor current $i_{L_{1}}$ (A)

It is noted in Fig. 5 that the current $\hat{i}_{L_{1}}$ estimated by the observer converges in finite time to the of the real current value $i_{L_{1}}$. And we observe from the Fig. 6 that the current $\hat{i_{L_{2}}}$ estimated by the observer converges in finite time to the real value $i_{L_{2}}$ even if the input signal changed. Besides Fig. 7 and Fig. 8 illustrates that the observation errors tend to zero in finite time. 


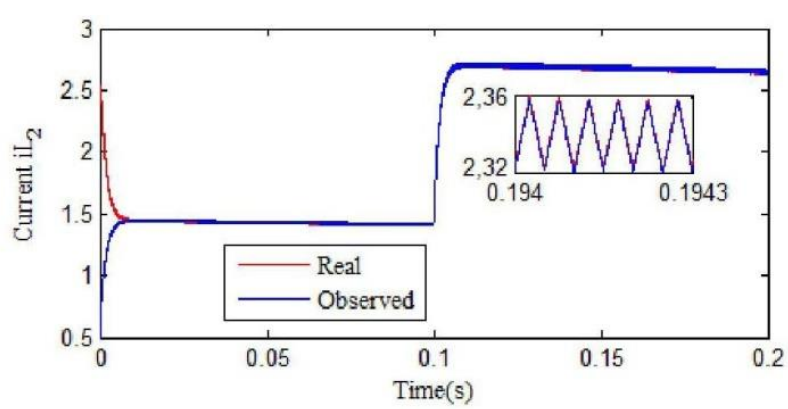

Fig. 6: Inductor current $i_{L_{2}}$ (A)

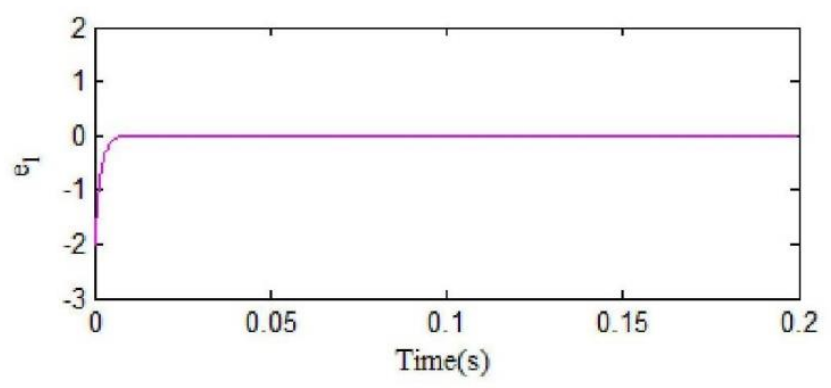

Fig. 7: Error $e_{1}=\hat{i}_{L_{2}}-i_{L_{2}}$

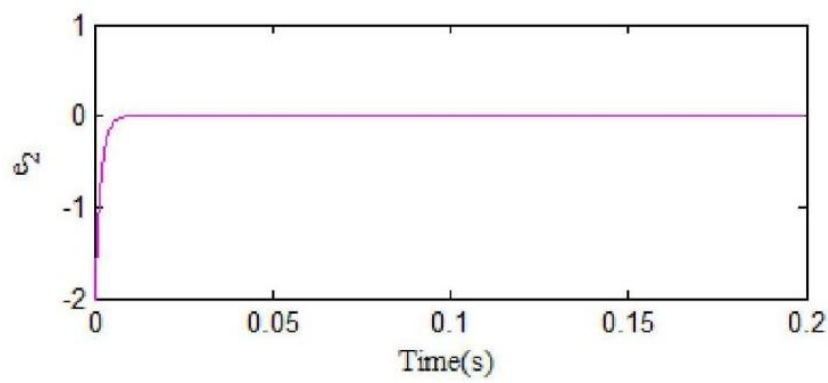

Fig. 8: Error $e_{2}=\hat{i_{L_{2}}}-i_{L_{2}}$

\section{CONCLUSION}

This paper deals with observability problems for IBC based on a hybrid system approach. A hybrid observer is proposed whose two types observer are coupled; the first one is the a homogeneous observer, and the second one is an estimator. A simulation work is performed to test the proposed observer structure againts against input signal variation. It's shown that the estimated currents converge towards the real currents values in finite time. But it must be mentioned that in this observer strucure design $q_{1}$ and $q_{2}$ are considered known at each instant of time. In a future work it will be assumed that those states are unknown. This case is a left inversion problem with $q_{1}$ and $q_{2}$ its input.

\section{REFERENCES}

[1] D. Urciuoli and C. Tipton, "Development of a $90 \mathrm{kw}$ bi-directional dc-dc converter for power dense applications," in Twenty-First Annual IEEE Applied Power Electronics Corference and Exposition, 2006. APEC'06., pp. 4-pp, IEEE, 2006.

[2] S. Waffler, J. Biela, and J. Kolar, "Output ripple reduction of an automotive multi-phase bi-directional dc-dc converter," in 2009 IEEE Energy Conversion Congress and Exposition, pp. 2184-2190, IEEE, 2009.

[3] J. A. A. Qahouq, "N-phase efficiency-based current sensing auto-tuning controller," in Applied Power Electronics Corference and Exposition, 2009. APEC 2009. Twenty-Fourth Annual IEEE, pp. 274-279, IEEE, 2009.

[4] L. Ni, D. J. Patterson, and J. L. Hudgins, "High power current sensorless bidirectional 16-phase interleaved dc-dc converter for hybrid vehicle application," IEEE Transactions on Power Electronics, vol. 27, no. 3, pp. 1141-1151, 2012.

[5] P.-W. Lee, Y.-S. Lee, D. K. Cheng, and X.-C. Liu, "Steady-state analysis of an interleaved boost converter with coupled inductors," IEEE Transactions on Industrial Electronics, vol. 47, no. 4, pp. 787-795, 2000.

[6] J. R. Pinheiro, H. A. Grundling, D. L. Vidor, and J. E. Baggio, "Control strategy of an interleaved boost power factor correction converter," in Power Electronics Specialists Corference, 1999. PESC 99. 30th Annual IEEE, vol. 1, pp. 137-142, IEEE, 1999.

[7] M. Veerachary, T. Senjyu, and K. Uezato, "Maximum power point tracking of coupled inductor interleaved boost converter supplied pv system," IEE Proceedings-Electric Power Applications, vol. 150, no. 1, pp. 71-80, 2003.

[8] B. A. Miwa, D. M. Otten, and M. Schlecht, "High efficiency power factor correction using interleaving techniques," in Applied Power Electronics Corference and Exposition, 1992. APEC'92. Conference Proceedings 1992., Seventh Annual, pp. 557-568, IEEE, 1992.

[9] Y. Buswig, Y. Mohammed, W. M. Utomo, A. Abu Bakar, and Z. A. Haron, "State-space derivation of an interleaved boost converter," 2014.

[10] H. El Fadil, F. Giri, J. Guerrero, and B. Salhi, "Adaptive control of interleaved boost converter for fuel cell energy," in Proceedings of the 2011 American Control Corference, pp. 3905-3910, IEEE, 2011.

[11] T. Beechner and J. Sun, "Optimal interleaved pulsewidth modulation considering sampling effects," in Applied Power Electronics Corference and Exposition (APEC), 2011 Twenty-Sixth Annual IEEE, pp. 18811887, IEEE, 2011.

[12] S. Lakshmi and S. R. Raja, "Observer-based controller for current mode control of an interleaved boost converter," Turkish Journal cf Electrical Engineering \& Computer Sciences, vol. 22, no. 2, pp. 341-352, 2014.

[13] M. Babaali, Switched linear systems: observability and observers. $\mathrm{PhD}$ thesis, Citeseer, 2004

[14] P. Riedinger, M. Sigalotti, and J. Daafouz, "On the observability of the flying capacitor converter," in Control Corference (ECC), 2009 Eurcpean, pp. 3605-3610, IEEE, 2009.

[15] S. Zhao and J. Sun, "Controllability and observability for time-varying switched impulsive controlled systems," International Journal cf Robust and Nonlinear Control, vol. 20, no. 12, pp. 1313-1325, 2010.

[16] Z. Sun, S. S. Ge, and T. H. Lee, "Controllability and reachability criteria for switched linear systems," Automatica, vol. 38, no. 5, pp. 775-786, 2002.

[17] M. Ghanes, F. Bejarano, and J.-P. Barbot, "On sliding mode and adaptive observers design for multicell converter," in 2009 American Control Corference, pp. 2134-2139, IEEE, 2009.

[18] A. Tanwani, H. Shim, and D. Liberzon, "Observability implies observer design for switched linear systems," in Proceedings of the 14th international corference on Hybrid systems: computation and control, pp. 312, ACM, 2011.

[19] A. Tanwani, H. Shim, and D. Liberzon, "Observability for switched linear systems: characterization and observer design," IEEE Transactions on Automatic Control, vol. 58, no. 4, pp. 891-904, 2013.

[20] W. Perruquetti, T. Floquet, and E. Moulay, "Finite-time observers: application to secure communication," IEEE Transactions on Automatic Control, vol. 53, no. 1, pp. 356-360, 2008. 
[21] W. Kang and J.-P. Barbot, "Discussions on observability and invertibility," IFAC Proceedings Volumes, vol. 40, no. 12, pp. 426-431, 2007.

[22] J. Lygeros, K. H. Johansson, S. N. Simic, J. Zhang, and S. S. Sastry, "Dynamical properties of hybrid automata," IEEE Transactions on automatic control, 2003.

[23] R. Goebel, J. Hespanha, A. R. Teel, C. Cai, and R. Sanfelice, "Hybrid systems: generalized solutions and robust stability," in Proc. 6th IFAC symposium in nonlinear control systems, pp. 1-12, 2004.

[24] R. Goebel, R. G. Sanfelice, and A. R. Teel, "Hybrid dynamical systems," IEEE Control Systems, vol. 29, no. 2, pp. 28-93, 2009.

[25] W. Kang, J.-P. Barbot, and L. Xu, "On the observability of nonlinear and switched systems," in Emergent problems in nonlinear systems and control, pp. 199-216, Springer, 2009.

[26] E. Bernuau, D. Efimov, E. Moulay, and W. Perruquetti, "Homogeneous continuous finite-time observer for the triple integrator," in Control Corference (ECC), 2015 European, pp. 903-908, IEEE, 2015. 